\title{
Closure to "Characterization and Engineering Properties of Dry and Ponded Class-F Fly Ash" by R. C. Bachus, M. Terzariol, C. Pasten, S. H. Chong, S. Dai, M. S. Cha, S. Kim, J. Jang, E. Papadopoulos, S. Roshankhah, L. Lei, A. Garcia, J. Park, A. Sivaram, F. Santamarina, X. Ren, and J. C. Santamarina
}

\section{Marco Terzariol}

Research Scientist in Marine Geotech, Département Ressources physiques et Ecosystèmes de fond de Mer (REM), Unité Géosciences Marines (GM), Laboratoire Aléas géologiques et Dynamique sédimentaire (LAD), Institut Français de Recherche pour l'Exploitation de la Mer, Centre Bretagne-ZI de la Pointe du Diable-CS 10070, Plouzané 29280, France; formerly, Research Scientist, Dept. of Earth Science and Engineering, King Abdullah Univ. of Science and Technology, Bldg. 5, Thuwal 23955-6900, Saudi Arabia (corresponding author). ORCID: https://orcid.org/0000-0001-5362 -1968. Email: marco.terzariol@ifremer.fr

\section{Junghee Park}

Research Scientist, Dept. of Earth Science and Engineering, King Abdullah Univ. of Science and Technology, Bldg. 5, Thuwal 23955-6900, Saudi Arabia. ORCID: https://orcid.org/0000-0001-7033-4653. Email: junghee .park@kaust.edu.sa

\section{J. Carlos Santamarina, M.ASCE}

Professor, Dept. of Earth Science and Engineering, King Abdullah Univ. of Science and Technology, Bldg. 5, Thuwal 23955-6900, Saudi Arabia. Email: carlos.santamarina@kaust.edu.sa
https://doi.org/10.1061/(ASCE)GT.1943-5606.0001986

We are grateful to the discussers for their comments. Without hesitation, contributions by Indian colleagues have played a critical role in today's understanding of fly ash properties and behavior. In fact, 14 references in the original paper recognize their work, including contributions by the discussers [data compilations referenced in our paper include data generated by the discussers and others-see also Kaniraj and Gayathri (2004) and Pandian (2004)]. Additional references provided by the discussers will benefit the readership, including the grain-size-based classification suggested in Prakash and Sridharan (2006).

Our experience with Atterberg limits agrees with that of the discussers. Still, the limits are informative. For example, fly ash specimens exhibit relatively high liquid limit (LL), low plastic limit (PL), and plot significantly lower than the A-line on the Casagrande chart. This is a clear indicator of accessible intragranular porosity, i.e., cenospheres [Fig. 1(c) in the original paper].

Furthermore, limits help cluster sediments into groups of similar behaviors. Consider the fall cone method as an index shear test, and

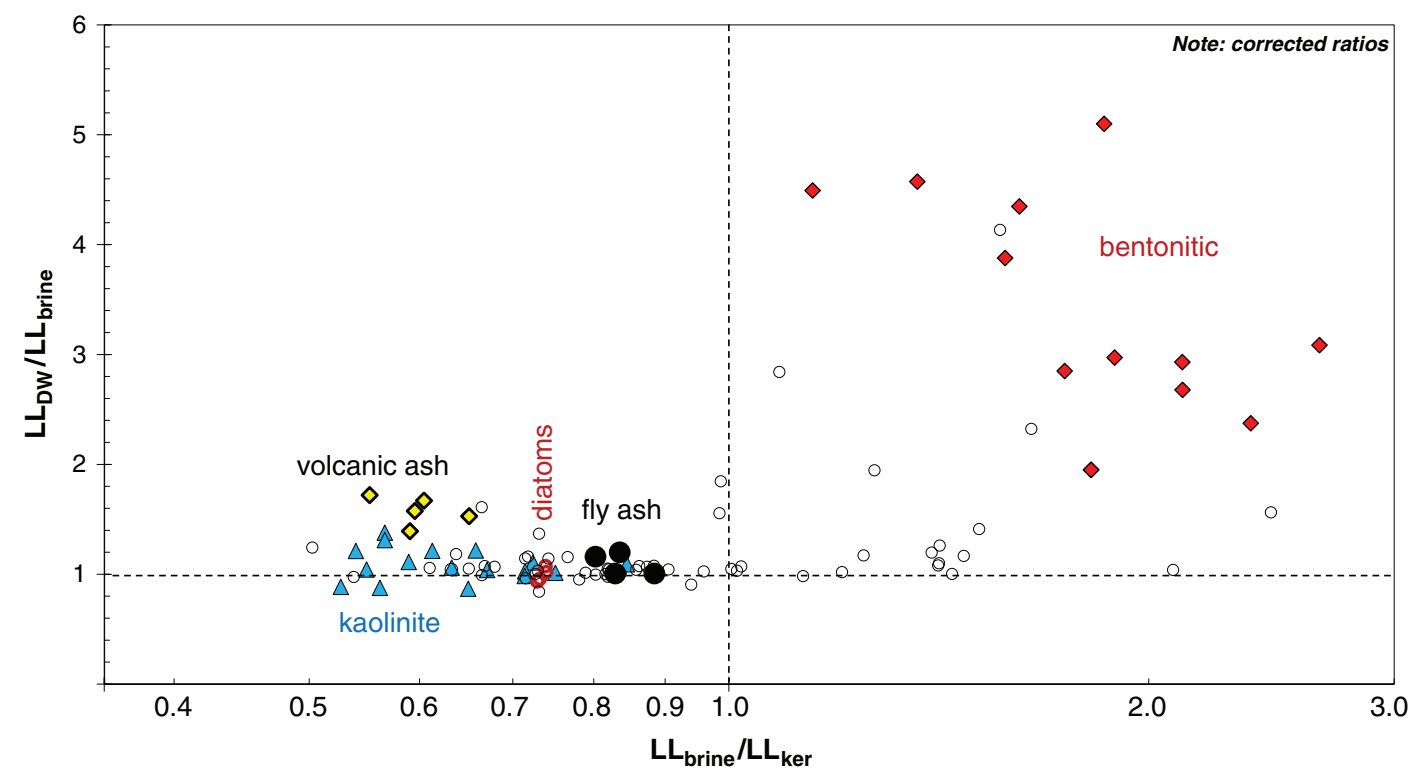

Fig. 1. (Color) Sediments and pore fluid chemistry. Solid black circles correspond to fly ash specimens reported in the original paper. Fly ash exhibits low electrical sensitivity to pore fluid chemistry. For reference, the plot distinguishes data for clays (bentonite and kaolinite) and sediments with intragranular porosity (volcanic ash and diatomaceous soils). Data for fly ash specimens cluster near diatoms and volcanic ash. $\mathrm{LL}_{\mathrm{brine}}, \mathrm{LL}_{\mathrm{ker}}$, and $\mathrm{LL}_{\mathrm{DW}}$ are the liquid limits determined using the fall cone method for sediment pastes prepared with brine, kerosene, and deionized water, respectively [values corrected for mass density—refer to Jang and Santamarina (2017)]. 
compare the liquid limits obtained with pastes prepared with water, brine (to collapse double layers), and kerosene (to alter van der Waals effects). These three liquid limits place fly ash specimens next to diatoms and volcanic ash (Fig. 1). In terms of the new fines classification chart by Jang and Santamarina (2016), fly ash specimens have low electrical sensitivity to pore fluid chemistry and low plasticity, hence fly ash classifies as L/L.

\section{References}

Jang, J., and J. C. Santamarina. 2016. "Fines classification based on sensitivity to pore-fluid chemistry." J. Geotech. Geoenviron. Eng. 142 (4): 06015018. https://doi.org/10.1061/(ASCE)GT.1943-5606.0001420.
Jang, J., and J. C. Santamarina. 2017. "Closure to 'Fines classification based on sensitivity to pore-fluid chemistry' by Junbong Jang and J. Carlos Santamarina." J. Geotech. Geoenviron. Eng. 143 (7): 07017013. https://doi.org/10.1061/(ASCE)GT.1943-5606 .0001694

Kaniraj, S. R., and V. Gayathri. 2004. "Permeability and consolidation characteristics of compacted fly ash." J. Energy Eng. 130 (1): 18-43. https://doi.org/10.1061/(ASCE)0733-9402(2004) 130:1(18).

Pandian, N. S. 2004. "Fly ash characterization with reference to geotechnical applications." J. Ind. Inst. Sci. 84 (6): 189-216.

Prakash, K., and A. Sridharan. 2006. "A geotechnical classification system for coal ashes." Proc. Inst. Civ. Eng. Geotech. Eng. 159 (2): 91-98. https://doi.org/10.1680/geng.2006.159.2.91. 